\title{
Effects of different vegetable oils on rumen fermentation and conjugated linoleic acid concentration in vitro
}

\author{
Amitava Roy, Guru Prasad Mandal and Amlan Kumar Patra \\ Department of Animal Nutrition, West Bengal University of Animal and Fishery Sciences, Belgachia, Kolkata - 700 037 , \\ West Bengal, India. \\ Corresponding author: Guru Prasad Mondal, e-mail: gpmandal1@gmail.com, \\ AR: amitavanutri07@gmail.com, AKP: patra_amlan@yahoo.com \\ Received: 30-05-2016, Accepted: 08-12-2016, Published online: 08-01-2017
}

doi: 10.14202/vetworld.2017.11-16 How to cite this article: Roy A, Mandal GP, Patra AK (2017) Effects of different vegetable oils on rumen fermentation and conjugated linoleic acid concentration in vitro, Veterinary World, 10(1): 11-16.

\begin{abstract}
Aim: The objective of this study was to investigate the effect of different vegetable oils on rumen fermentation and concentrations of beneficial cis-9 trans-11 C18:2 conjugated linoleic acid (CLA) and trans-11 C18:1 fatty acid (FA) in the rumen fluid in an in vitro condition.

Materials and Methods: Six vegetable oils including sunflower, soybean, sesame, rice bran, groundnut, and mustard oils were used at three dose levels $(0 \%, 3 \%$ and $4 \%$ of substrate dry matter [DM] basis) in three replicates for each treatment in a completely randomized design using $6 \times 3$ factorial arrangement. Rumen fluid for microbial culture was collected from four goats fed on a diet of concentrate mixture and berseem hay at a ratio of 60:40 on DM basis. The in vitro fermentation was performed in $100 \mathrm{ml}$ conical flakes containing $50 \mathrm{ml}$ of culture media and $0.5 \mathrm{~g}$ of substrates containing $0 \%, 3 \%$ and $4 \%$ vegetable oils.
\end{abstract}

Results: Oils supplementation did not affect $(\mathrm{p}>0.05)$ in vitro DM digestibility, and concentrations of total volatile FAs and ammonia-N. Sunflower oil and soybean oil decreased $(\mathrm{p}<0.05)$ protozoal numbers with increasing levels of oils. Other oils had less pronounced effect ( $\mathrm{p}>0.05$ ) on protozoal numbers. Both trans-11 C18:1 FA and cis-9, trans-11 CLA concentrations were increased $(\mathrm{p}<0.05)$ by sunflower and soybean oil supplementation at $4 \%$ level with the highest concentration observed for sunflower oil. The addition of other oils did not significantly ( $\mathrm{p}>0.05)$ increase the trans-11 C18:1 FA and cis-9, trans-11 CLA concentrations as compared to the control. The concentrations of stearic, oleic, linoleic, and linolenic acids were not altered $(\mathrm{p}>0.05)$ due to the addition of any vegetable oils.

Conclusion: Supplementation of sunflower and soybean oils enhanced beneficial trans-11 C18:1 FA and cis-9, trans-11 CLA concentrations in rumen fluid, while sesame, rice bran, groundnut, and mustard oils were ineffective in this study.

Keywords: conjugated linoleic acid, goat, rumen fluid, vaccenic acid, vegetable oil.

\section{Introduction}

Enrichment of the nutraceutical quality of meat and milk of ruminant origins has been of growing interests among the researchers using dietary approaches due to increasing demands of healthy foods by the consumers [1-4]. The healthy fatty acids (FA), especially conjugated linoleic acids (CLAs) and n-3 polyunsaturated FA (eicosapentaenoic acid and docosahexaenoic acid) in foods for human consumption have shown several potential health benefits in several studies $[1,5]$. Another FA, trans-11 C18:1 (also called vaccenic acid; VA) is also associated with decreased risks of cardiovascular disease $[6,7]$. Milk and meat from ruminants are the main natural sources of CLAs [8]. However, usual dietary intakes of meat and milk are not adequate in fulfilling the requirement of cis-9, trans-11 CLA to achieve expected health benefits [1]. Therefore, several studies over the last two decades have been conducted

Copyright: Roy, et al. Open Access. This article is distributed under the terms of the Creative Commons Attribution 4.0 International License (http://creativecommons.org/licenses/by/4.0/), which permits unrestricted use, distribution, and reproduction in any medium, provided you give appropriate credit to the original author(s) and the source, provide a link to the Creative Commons license, and indicate if changes were made. The Creative Commons Public Domain Dedication waiver (http://creativecommons.org/ publicdomain/zero/1.0/) applies to the data made available in this article, unless otherwise stated. for enhancing the cis-9, trans-11 CLA content in milk and meat of ruminants by supplementing linoleic and linolenic acid rich oils and oil seeds, which increase the availability of precursors of CLA synthesis $[9,10]$, and modulating rumen microbiota and metabolism responsible for biohydrogenation of unsaturated $\mathrm{C} 18$ FA to stearic acid $[2,3]$.

The cis-9, trans-11 CLA in meat and milk is partly absorbed from the gut after partial biohydrogenation of linoleic acid in the rumen [9]. The major part of this CLA is synthesized endogenously by the enzyme delta-9-desaturase in the animal tissues from VA, which is also a biohydrogenation intermediate of oleic, linoleic, and linolenic acids [11,12]. Different oils differ in their ability to increase the concentrations of these beneficial FA in rumen fluid and subsequently in meat and milk.

Therefore, this study was conducted to investigate the effects of different types of vegetable oils on rumen fermentation and concentration of CLAs and VA in rumen fluid in vitro.

\section{Materials and Methods}

\section{Ethical approval}

The experiment was approved by the Institutional Animal Ethics Committee for Animal Care and 
Management, West Bengal University of Animal and Fishery Sciences, Kolkata, West Bengal, India.

\section{Experimental design}

Six different vegetable oils including sunflower, soybean, sesame, rice bran, groundnut, and mustard oils were procured from local grocery stores. These vegetable oils were used at three dose levels $(0 \%, 3 \%$, and $4 \%$ of substrate on dry matter [DM] basis) in three replicates for each treatment in a completely randomized design with a $6 \times 3$ factorial arrangement. Low concentrations of these oils as precursors of CLA in biohydrogenation process may not increase the CLA concentration in rumen fluid, while high concentration could inhibit overall rumen fermentation process [13]. We hypothesized that oils at 3-4\% levels may enhance CLA concentration without affecting rumen fermentation.

\section{Rumen incubation}

Rumen liquor was collected by a stomach tube from four goats fed on a diet of concentrate mixture and berseem hay at a 60:40 ratio on DM basis. The rumen liquor was collected during morning before feeding and watering, transported in insulated flasks under anaerobic conditions to the laboratory, pooled in equal proportions and used as a source of inoculums. The fermentation process was conducted in $100 \mathrm{ml}$ conical flaskes containing $50 \mathrm{ml}$ of culture media (1:4 ratio of rumen fluid and phosphate-bicarbonate buffer [14], purged with $\mathrm{CO}_{2}$ ), $0.5 \mathrm{~g}$ of substrates supplemented with $0 \%, 3 \%, 4 \%$ of each vegetable oil. Concentrate mixture (crude protein - 17.4\%; neutral detergent fiber - $38.1 \%$; ether extract $-1.12 \%$ on DM basis) and berseem hay (crude protein - 13.1\%; neutral detergent fiber - $67.2 \%$; ether extract $-1.21 \%$ on DM basis) at 60:40 ratio on DM basis were used as substrates. After flushing $\mathrm{CO}_{2}$ in the flasks for $5 \mathrm{~min}$, a cork fitted with Bunsen gas release valve was tightly placed over the flasks and were incubated at $39^{\circ} \mathrm{C}$ for $24 \mathrm{~h}$ in a shaking incubator $(105 \mathrm{rpm})$. After termination of incubation, the $\mathrm{pH}$ of the incubated media was determined by a digital $\mathrm{pH}$ meter, and then the content of the flasks was mixed properly and $1 \mathrm{ml}$ of digestate was collected for protozoal counts. The remaining content was filtered through Gouch crucible (Grade I) and residual DM was analyzed to determine in vitro DM digestibility (IVDMD) as done earlier [15]. $15 \mathrm{ml}$ of the filtrate was collected and stored at $-20^{\circ} \mathrm{C}$ for further analysis.

\section{Laboratory analyses}

For protozoa count, $1 \mathrm{ml}$ sample was mixed with $1 \mathrm{ml}$ methyl green formal saline solution. The stained sample was kept overnight, and protozoal numbers were counted microscopically using Neubauer counting chamber following the procedure of Kamra et al. [16]. Total volatile FA (VFA) was quantified as per the procedure of Barnett and Reid [17]. Ammonia-N was estimated by the micro-Kjeldahl method [18].

FA concentrations in feeds, vegetable oils, and rumen fluid were measured for control and 4\% oil supplemented samples following the method of O'Fallon et al. [19] with slight modification, which has also been described previously [3]. $20 \mu 1$ sample was placed into a $16 \mathrm{~mm} \times 125 \mathrm{~mm}$ screw-cap Pyrex culture tube to which $0.5 \mathrm{ml}$ of the C13:0 internal standard (0.5 mg of C13:0/mL of methanol), $0.35 \mathrm{ml}$ of $10 \mathrm{~N} \mathrm{KOH}$ in water, and $2.65 \mathrm{ml}$ of $\mathrm{MeOH}$ were added. The tube was incubated at $55^{\circ} \mathrm{C}$ for $1.5 \mathrm{~h}$ with vigorous handshaking for $5 \mathrm{~s}$ every $20 \mathrm{~min}$ to properly permeate, dissolve and hydrolyze the FA in the samples. After cooling below room temperature in a cold tap water bath, $0.29 \mathrm{ml}$ of $24 \mathrm{~N} \mathrm{H}_{2} \mathrm{SO}_{4}$ in water was added. The tube was mixed by inversion and with precipitated $\mathrm{K}_{2} \mathrm{SO}_{4}$ present was incubated again at $55^{\circ} \mathrm{C}$ for $1.5 \mathrm{~h}$ with hand-shaking for $5 \mathrm{~s}$ every $20 \mathrm{~min}$. After FA methyl ester (FAME) synthesis, the tube was cooled in a cold tap water bath, $1.5 \mathrm{ml}$ of hexane was added, and the tube was vortex-mixed for $5 \mathrm{~min}$ on a multi-tube vortex. The tube was centrifuged for $5 \mathrm{~min}$ in a tabletop centrifuge at $2500 \mathrm{rpm}$, and the hexane layer, containing the FAME, was placed into a vial. The vial was capped and placed at $-20^{\circ} \mathrm{C}$ until analysis. Concentrations of FA in the samples were analyzed in a gas chromatography fitted with capillary column $(100 \mathrm{~m} \times 0.25 \mathrm{~mm} \times 0.20 \mu \mathrm{m})$. Helium was used as a carrier gas. FAs were identified by comparing their retention time with the FAME standard.

\section{Statistical analysis}

The data analysis was performed by SPSS, version 16 [20] software. Rumen fermentation and FA concentration data were analyzed in two-way ANOVA with oil type, dose levels and their interaction as the main effects in $6 \times 3$ and $6 \times 2$ factorial arrangements, respectively. No variable except protozoal counts was affected ( $>0.05)$ by the interaction effect. Then, data were analyzed in one-way ANOVA among the dose levels and oil type. Tukey's test was used to find out the differences among the dose levels.

\section{Results}

Mustard oil contained the highest concentration of C18:3 FA, while C18:2 FA content was higher in sunflower oil, followed by soybean oil (Table-1). Rice bran oil was richest in C18:1 and C16:0 FA. Ruminal fermentation parameters are presented in Table-2. Oils supplementation at $3 \%$ and $4 \%$ level did not influence IVDMD, $\mathrm{pH}$, and concentrations of total VFA and ammonia-N in rumen fluid. Protozoal counts were affected by oil $\times$ level interaction. Sunflower oil and soybean oil decreased $(\mathrm{p}<0.05)$ protozoal numbers with increasing levels of oils (Table-3). Other oils had less pronounced effect on protozoal numbers. The effects of different vegetable oils on FA concentrations in rumen fluid are presented in Table-4. Both VA (trans$11 \mathrm{C} 18: 1)$ and cis-9, trans-11 CLA concentrations were improved $(\mathrm{p}<0.05)$ by sunflower and soybean oil supplementation at $4 \%$ level. The increment of these FA was greater for sunflower oil. Addition of other oils did not significantly increase the VA concentrations as 
Table-1: FA composition of vegetable oils and substrate ( $\mathrm{g} / 100 \mathrm{~g}$ of total FAs).

\begin{tabular}{lccccccrr}
\hline FA & \multicolumn{9}{c}{ Vegetable oil } & Concentrate & Berseem \\
\cline { 2 - 6 } & Rice bran & Soybean & Sesame & Mustard & Sunflower & Groundnut & & \\
\hline C14:0 & 0.39 & 0.09 & 0.03 & 0.14 & 0.33 & 0.08 & - & 16.8 \\
C16:0 & 20.7 & 12.2 & 9.73 & 4.16 & 8.50 & 13.1 & 19.0 \\
C16:1 & 0.23 & 0.08 & 0.24 & 0.23 & 0.33 & 0.14 & 0.52 & 0.30 \\
C18:0 & 2.66 & 3.27 & 5.10 & 1.83 & 7.40 & 4.00 & 7.21 & 5.03 \\
C18:1 & 40.0 & 29.4 & 37.2 & 13.6 & 25.7 & 43.2 & 29.3 & 3.22 \\
C18:2 & 34.4 & 45.8 & 39.6 & 34.0 & 54.2 & 35.8 & 45.9 & 11.3 \\
C18:3 & 0.56 & 3.78 & 1.57 & 9.28 & 0.32 & 0.74 & 2.03 & 30.9 \\
\hline
\end{tabular}

FA=Fatty acid

Table-2: Effects of vegetable oil supplementation on rumen fermentation in the rumen fluid after $24 \mathrm{~h}$ of incubation.

\begin{tabular}{|c|c|c|c|c|c|}
\hline \multirow[t]{2}{*}{ Vegetable oil } & \multicolumn{3}{|c|}{ Dose level } & \multirow[t]{2}{*}{ SEM } & \multirow[t]{2}{*}{ p value } \\
\hline & $0 \%$ & $3 \%$ & $4 \%$ & & \\
\hline \multicolumn{6}{|l|}{ IVDMD (\%) } \\
\hline Mustard & 46.4 & 45.8 & 45.8 & 0.65 & 0.729 \\
\hline Groundnut & 45.9 & 45.2 & 45.0 & 0.26 & 0.351 \\
\hline Sunflower & 45.0 & 44.8 & 43.6 & 0.36 & 0.207 \\
\hline Sesame & 46.0 & 45.8 & 45.7 & 0.35 & 0.531 \\
\hline Soybean & 45.2 & 44.3 & 43.2 & 0.58 & 0.185 \\
\hline Rice bran & 45.9 & 44.8 & 46.5 & 0.22 & 0.296 \\
\hline SEM & 0.23 & 0.61 & 0.89 & & \\
\hline$p$ value & 0.857 & 0.424 & 0.479 & & \\
\hline \multicolumn{6}{|c|}{ Total VFA $(\mathrm{mmol} / \mathrm{dl})$} \\
\hline Mustard & 5.58 & 5.42 & 5.50 & 0.05 & .640 \\
\hline Anut & 5.42 & 5.38 & 5.44 & 0.04 & 0.554 \\
\hline Sunflower & 5.37 & 5.36 & 5.15 & 0.05 & 0.361 \\
\hline Sesame & 5.33 & 5.55 & 5.49 & 0.09 & 0.846 \\
\hline Soybean & 5.42 & 5.28 & 5.46 & 0.08 & 0.262 \\
\hline Rice bran & 5.39 & 5.45 & 5.32 & 0.05 & 0.450 \\
\hline SEM & 0.07 & 0.08 & 0.10 & & \\
\hline $\mathrm{p}$ value & 0.778 & 0.692 & 0.623 & & \\
\hline \multicolumn{6}{|l|}{$\mathrm{pH}$} \\
\hline Mustard & 6.67 & 6.63 & 6.53 & 0.03 & 0.813 \\
\hline Groundnut & 6.53 & 6.56 & 6.67 & 0.04 & 0.732 \\
\hline Sunflower & 6.60 & 6.57 & 6.40 & 0.05 & 0.708 \\
\hline Sesame & 6.53 & 6.53 & 6.50 & 0.02 & 0.892 \\
\hline Soybean & 6.53 & 6.47 & 6.50 & 0.04 & 0.655 \\
\hline Rice bran & 6.53 & 6.63 & 6.56 & 0.04 & 0.647 \\
\hline SEM & 0.08 & 0.05 & 0.06 & & \\
\hline$p$ value & 0.904 & 0.718 & 0.754 & & \\
\hline \multicolumn{6}{|c|}{ Ammonia-N (mg/c } \\
\hline Mustard & 8.32 & 8.09 & 8.27 & 0.05 & 0.424 \\
\hline Groundnut & 8.07 & 8.20 & 8.30 & 0.06 & 0.375 \\
\hline Sunflower & 8.07 & 8.20 & 8.30 & 0.06 & 0.408 \\
\hline Sesame & 8.31 & 8.39 & 8.16 & 0.06 & 0.666 \\
\hline Soybean & 8.38 & 8.06 & 8.26 & 0.07 & 0.307 \\
\hline Rice bran & 8.34 & 7.96 & 8.09 & 0.08 & 0.266 \\
\hline SEM & 0.09 & 0.08 & 0.05 & & \\
\hline$p$ value & 0.670 & 0.512 & 0.540 & & \\
\hline
\end{tabular}

IVDMD $=$ In vitro dry matter digestibility, VFA=Volatile fatty acids, SEM $=$ Standard error of mean

compared to the control. The concentrations of stearic, oleic, linoleic, and linolenic acids were not $(\mathrm{p}>0.05)$ altered due to addition of any vegetable oils.

\section{Discussion}

Oil supplementation sometimes exerts detrimental effects on digestibility and VFA production due to general inhibitory effect of oils on rumen microbiota [21]. In this study, rumen fermentation was not affected, which was likely due to low concentration of oils used. Usually, oils or fats at concentrations of $4 \%$ in the diet do not affect rumen fermentation and may improve production performance of ruminants $[13,22]$. Soybean oil at $6 \%$ of diet did not influence DM degradability and total VFA concentrations in vitro [23]. Soybean oil-fish oil and rapeseed-fish oil blends reduced IVDMD when concentrations of oil were $>5 \%$ of the diet, but not at lower concentration [24]. Sunflower oil and soybean oil inhibited the growth of protozoa, which was also observed in other studies [21] and is influenced by the degree of unsaturation of FA with greater unsaturation causing higher inhibitory effects on protozoa. Despite inhibition of protozoa, which may lower ammonia concentration by sunflower oil and soybean oil, ammonia concentration was not changed. This was probably due to lower time of incubation and low dose of oils to influence ammonia concentration by low number of protozoa. Gómez-Cortés et al. [23] reported that supplementation of soybean oil at $6 \%$ of the diet tended to decrease ammonia concentration in vitro.

Vegetable oils rich in C18:2 cis-9, cis-12 (linoleic acid) and C18:3 cis-9, cis-12, cis-15 (linolenic acid) FA could potentially increase VA and CLA concentration in the rumen fluid by bacteria biohydrogenation [10]. Linoleic acid has been shown to be converted to C18:2 cis-9, tran-11 and C18:1 tran-11 while linolenic acid can be converted to cis- 9 , trans-11, cis-15 C18:3 conjugated triene, then to trans-11, cis-15 C18:2, and finally to an octadecenoic acid that is either trans-11, trans-15 C18:2, or cis-15 C18:1 via rumen biohydrogenation [25]. The supplementation of soybean oil and sunflower oil enhanced VA and cis-9, trans-11 CLA concentrations in rumen fluid to a great extent. El-Sherbiny et al. [24] also found that VA and cis-9, trans-11 C18:2 concentrations in rumen fluid were increased by supplementation of soybean and rapeseed oil at $5 \%$ of DM, but not at 3\% of DM. In another study, concentration of cis-9, trans-11 CLA was not altered, but the concentration of VA was increased in the in vitro rumen fluid by supplementation of soybean-fish oil blend at 3\% of diet [26]. From this study and other studies, it appears that supplementation of vegetable oils at $4 \%$ or greater levels would be needed 
Table-3: Effects of vegetable oil supplementation on protozoal population in the rumen liquor after $24 \mathrm{~h}$ of incubation.

\begin{tabular}{|c|c|c|c|c|c|c|c|}
\hline \multirow[t]{2}{*}{ Vegetable oil } & \multicolumn{3}{|c|}{ Dose level } & \multirow[t]{2}{*}{ SEM } & \multicolumn{3}{|c|}{ p value } \\
\hline & $0 \%$ & $3 \%$ & $4 \%$ & & Oil & Dose level & Oil $\times$ dose \\
\hline Mustard & 36.2 & $35.2^{x}$ & $33.5^{x}$ & 1.21 & 0.264 & 0.005 & 0.108 \\
\hline Groundnut & 35.3 & $36.2^{x}$ & $34.7^{x}$ & 0.61 & & & \\
\hline Sunflower & $36.1^{a}$ & $31.5^{\text {by }}$ & $27.2^{c y}$ & 1.51 & & & \\
\hline Sesame & 36.3 & $34.9^{x}$ & $34.3^{x}$ & 1.03 & & & \\
\hline Soybean & $36.2^{a}$ & $33.2^{a b x y}$ & $30.9^{\text {bxy }}$ & 1.19 & & & \\
\hline Rice bran & 36.5 & $33.1^{x y}$ & $32.2^{x}$ & 0.91 & & & \\
\hline SEM & 0.25 & 1.15 & 1.40 & & & & \\
\hline $\mathrm{p}$ value & 0.844 & 0.042 & 0.027 & & & & \\
\hline
\end{tabular}

$a, b, c$ Means with different superscript letters within a row differ significantly $(p<0.05)$. ${ }^{x y}$ Means with different superscripts letters within a column differ significantly $(p<0.05)$. SEM=Standard error of mean

Table-4: Effect of vegetable oil supplementation on FA profile (\% of total FAs) in the rumen fluid after $24 \mathrm{~h}$ of incubation.

\begin{tabular}{|c|c|c|c|c|}
\hline \multirow[t]{2}{*}{ Vegetable oil } & \multicolumn{2}{|c|}{ Dose level } & \multirow[t]{2}{*}{ SEM } & \multirow[t]{2}{*}{ p value } \\
\hline & $0 \%$ & $4 \%$ & & \\
\hline \multicolumn{5}{|c|}{ Stearic acid (C18:0) } \\
\hline Mustard & 25.3 & 26.7 & 0.50 & 0.464 \\
\hline Groundnut & 25.4 & 24.7 & 0.41 & 0.322 \\
\hline Sunflower & 26.4 & 23.1 & 0.80 & 0.160 \\
\hline Sesame & 26.2 & 25.8 & 0.60 & 0.377 \\
\hline Soybean & 25.9 & 23.4 & 0.70 & 0.133 \\
\hline Rice bran & 25.9 & 28.2 & 1.22 & 0.157 \\
\hline SEM & 0.28 & 1.16 & & \\
\hline $\mathrm{p}$ value & 0.816 & 0.408 & & \\
\hline \multicolumn{5}{|c|}{ Oleic acid (cis-9 C18:1) } \\
\hline Mustard & 15.5 & 18.2 & 0.90 & .106 \\
\hline Groundnut & 15.8 & 18.3 & 0.64 & 0.089 \\
\hline Sunflower & 16.7 & 13.9 & 1.30 & 0.154 \\
\hline Sesame & 16.7 & 18.3 & 0.44 & 0.219 \\
\hline Soybean & 16.7 & 15.6 & 1.00 & 0.431 \\
\hline Rice bran & 17.0 & 14.4 & 0.80 & 0.136 \\
\hline SEM & 0.46 & 1.53 & & \\
\hline $\mathrm{p}$ value & 0.613 & 0.340 & & \\
\hline \multicolumn{5}{|c|}{ VA (trans-11 C18:1) } \\
\hline Mustard & 6.57 & $6.95^{z}$ & 0.13 & 0.709 \\
\hline Groundnut & 6.66 & $7.10^{z}$ & 0.13 & 0.311 \\
\hline Sunflower & $6.61^{a}$ & $9.34^{\mathrm{b}, \mathrm{x}}$ & 0.54 & 0.034 \\
\hline Sesame & 6.65 & $7.15^{z}$ & 0.20 & 0.220 \\
\hline Soybean & $6.74^{\mathrm{a}}$ & $8.10^{\text {by }}$ & 0.33 & 0.014 \\
\hline Rice bran & 6.65 & $7.36^{y z}$ & 0.18 & 0.192 \\
\hline SEM & 0.06 & 0.85 & & \\
\hline $\mathrm{p}$ value & 0.772 & 0.026 & & \\
\hline \multicolumn{5}{|c|}{ Linoleic acid (cis-9, cis-12 } \\
\hline \multicolumn{5}{|l|}{ C18:2) } \\
\hline Mustard & 8.49 & 7.69 & 0.29 & 0.506 \\
\hline Groundnut & 8.45 & 7.86 & 0.34 & 0.457 \\
\hline Sunflower & 8.45 & 9.85 & 0.54 & 0.366 \\
\hline Sesame & 8.50 & 7.66 & 0.24 & 0.234 \\
\hline Soybean & 8.40 & 9.29 & 0.34 & 0.207 \\
\hline Rice bran & 8.97 & 8.20 & 0.12 & 0.580 \\
\hline SEM & 0.22 & 0.90 & & \\
\hline $\mathrm{p}$ value & 0.790 & 0.403 & & \\
\hline \multicolumn{5}{|c|}{ CLA (cis-9, trans-11 C18:2) } \\
\hline Mustard & 0.31 & $0.35^{z}$ & 0.01 & 0.154 \\
\hline Groundnut & 0.31 & $0.34^{z}$ & 0.01 & 0.137 \\
\hline Sunflower & $0.32^{\mathrm{a}}$ & $0.44^{\mathrm{bx}}$ & 0.02 & 0.026 \\
\hline Sesame & 0.31 & $0.35^{z}$ & 0.01 & 0.330 \\
\hline Soybean & $0.31^{\mathrm{a}}$ & $0.41^{\text {by }}$ & 0.02 & 0.019 \\
\hline Rice bran & 0.31 & $0.36^{z}$ & 0.02 & 0.204 \\
\hline SEM & 0.02 & 0.01 & & \\
\hline$p$ value & 0.885 & 0.039 & & \\
\hline
\end{tabular}

a,bMeans with different superscript letters in a row differ significantly $(p<0.05)$. $x, y, z$ Means with different superscript letters in a column within a fatty acid differ significantly $(p<0.05) . S E M=$ Standard error of mean, $C L A=$ Conjugated linoleic acid, VA=Vaccenic acid, FA=Fatty acid to achieve a significant effect on VA and cis-9, trans11 CLA concentrations in rumen fluid in vitro. In vivo studies in lambs, heifers and goats have reported the enhancement of the CLA content in muscle and adipose tissue with addition of vegetable oils or seeds (safflower oil added up to $6 \%$ of the diet DM [27]; sunflower and linseed oils each at about $2.82 \%$ of diet DM [28]; sunflower and soybean oils each at $4.5 \%$ of the diet DM [29]). In lactating goats, the concentration of CLA in milk increased with safflower and linseed oil supplementation at $5 \%$ of diet [30]. Rice bran oil added in the concentrate mixture up to $6 \%$ linearly increased cis-9, trans-11 CLA and total CLA in milk of dairy cows [31]. Dai et al. [32] reported that the inclusion of vegetable oils (rapeseed, peanut, and sunflower seed oils each added at $2 \%$ of diet DM) increased the concentration of cis-9, trans-11 CLA. Increased VA and CLA concentrations in rumen fluid are attributed to partial biohydrogenation of linoleic and linolenic acid by ruminal microorganisms in response to oil supplementation [25]. Despite increases in concentrations of cis-9, trans-11 CLA and trans-11 C18:1 FA, the concentrations of C18:0 FA were not changed. The reason is unknown but it may be due to short duration of incubation. Again, concentrations of cis-9, trans-11 CLA were not significantly increased by sesame oil containing 39.6\% C18:2 FA though soybean oil containing 45.8\% C18:2 FA enhanced cis-9, trans-11 CLA in the rumen fluid. This may be attributed to the marginally low concentration of C18:2 FA in sesame oil. In a study by Dai et al. [32] also, peanut oil supplementation containing 26.9\% C18:2 FA of total FA of diet increased cis-9, trans-11 CLA in milk of cows compared with rapeseed oil containing 31.6\% C18:2 FA of total FA in diet DM. With other in vitro studies, this in vitro study has many shortcomings such as short incubation time, absence of digesta flow, low density of contents in the media, and continuous buffering activity, which would not represent true in vivo conditions. Nonetheless, in vitro study is useful to find out preliminary findings, which are required to be confirmed in long-term animal studies.

\section{Conclusion}

Supplementation of vegetable oils rich in linoleic acid and linolenic acid such as sunflower oil and 
soybean oil at a dose of $4 \%$ of the diet could greatly increase beneficial cis-9, trans-11 CLA and VA concentrations in rumen fluid. These healthy FA after absorption from the intestine may be enriched in milk and meat of ruminants, but this should be confirmed in vivo animal experimentations.

\section{Authors' Contributions}

GPM and AR carried out the experiment design. AR participated in practical work. AKP and GPM performed statistical analysis, data interpretation and writing of the manuscript. All authors read and approved the final manuscript.

\section{Acknowledgments}

We are grateful to the Department of Biotechnology, Government of India for providing financial assistance under the project No: BR/PR11422/ AAQ/01/380/2008 "Production of CLA rich goat meat through dietary supplementation of vegetable oil and plant extract."

\section{Competing Interests} interests.

The authors declare that they have no competing

\section{References}

1. Daley, C.A., Abbott, A., Doyle, P.S., Nader, G.A. and Larson, S. (2010) A review of fatty acid profiles and antioxidant content in grass-fed and grain-fed beef. Nutr. J., 9: 10. DOI: 10.1186/1475-2891-9-10.

2. Patra, A.K. (2014) Exploring the benefits of feeding tannin containing diets for enhancing the nutritional values of milk and meat of ruminants. Indian J. Anim. Health, 53: 63-76.

3. Mandal, G.P., Roy, A. and Patra, A.K. (2014) Effects of feeding plant additives rich in saponins and essential oils on the performance, carcass traits and conjugated linoleic acid concentrations in muscle and adipose tissues of Black Bengal goats. Anim. Feed Sci. Technol., 197: 76-84.

4. Mandal, G.P., Roy, A. and Patra, A.K. (2016) Effects of plant extracts rich in tannins, saponins and essential oils on rumen fermentation and conjugated linoleic acid conentrations in vitro. Indian J. Anim. Health, 55: 49-60.

5. Benjamin, S. and Spener, F. (2009) Conjugated linoleic acids as functional food: An insight into their health benefits. Nutr. Metab. (Lond.), 6: 36. DOI: 10.1186/1743-7075-6-36.

6. Field, C.J., Blewett, H.H., Proctor, S. and Vine, D. (2009) Human health benefits of vaccenic acid. Appl. Physiol. Nutr. Metab., 34: 979-991.

7. Wang, Y., Jacome-Sosa, M.M. and Proctor, S.D. (2012) The role of ruminant trans fat as a potential nutraceutical in the prevention of cardiovascular disease. Food Res. Int., 46: 460-468.

8. Chin, S.F., Liu, W., Storkson, J.M., Ha, Y.L. and Pariza, W.M. (1992) Dietary sources of conjugated dienoic isomers of linoleic acid, a newly recognized class of anticarcinogens. J. Food Compost. Anal., 5: 185-197.

9. Lock, A.L. and Bauman, D.E. (2004) Modifying milk fat composition of dairy cows to enhance fatty acids beneficial to human health. Lipids, 39: 1197-1206.

10. Shingfield, K.J., Bonnet, M. and Scollan, N.D. (2013) Recent developments in altering the fatty acid composition of ruminant-derived foods. Anim. Suppl., 1: 132-162.

11. Griinari, J.M., Corl, B.A., Lacy, S.H., Chouinard, P.Y., Nurmela, K.V.V. and Bauman, D.E. (2000) Conjugated linoleic acid is synthesized endogenously in lactating dairy cows by $\Delta^{9}$-desaturase. J. Nutr., 130: 2285-2291.

12. Mosley, E.E., Powell, G.L., Riley, M.B. and Jenkins, T.C. (2002) Microbial biohydrogenation of oleic acid to trans isomers in vitro. J. Lipid Res., 43: 290-296.

13. Patra, A.K. (2014) A meta-analysis of the effect of dietary fat on enteric methane production, digestibility and rumen fermentation in sheep, and a comparison of these responses between cattle and sheep. Livest. Sci., 162: 97-103.

14. Menke, K.H. and Steingass, H. (1988) Estimation of the energetic feed value from chemical analysis and in vitro gas production using rumen fluid. Anim. Res. Dev., 28: 7-55.

15. Patra, A.K., Stiverson, J. and Yu, Z. (2012) Effects of quillaja and yucca saponins on communities and select populations of rumen bacteria and archaea, and fermentation in vitro. J. Appl. Microbiol., 113: 1329-1340.

16. Kamra, D.N., Sawal, R.K., Pathak, N.N., Kewalramani, N. and Agarwal, N. (1991) Diurnal variation in ciliate protozoa in the rumen of blackbuck (Antilope cervicapra). Lett. Appl. Microbiol., 13: 165-167.

17. Barnett, J.G.A. and Reid, R.L. (1956) Studies on the production of volatile fatty acids from the grass by rumen liquor in an artificial rumen. J. Agric. Sci., 48: 315-321.

18. AOAC. (2005) Official Methods of Analysis. $18^{\text {th }}$ ed. Association of Official Analytical Chemists, Washington, DC.

19. O'Fallon, J.V., Busboom, J.R., Nelson, M.L. and Gaskins, C.T. (2007) A direct method for fatty acid methyl ester synthesis: Application to wet meat tissues, oils, and feedstuffs. J. Anim. Sci., 85: 1511-1521.

20. SPSS. (1996) Statistical Packages for Social Sciences. Version 7.5. SPSS Inc., USA, IL.

21. Patra, A.K. and Yu, Z. (2013) Effects of coconut and fish oils on ruminal methanogenesis, fermentation, and abundance and diversity of microbial populations in vitro. J. Dairy Sci., 96: 1782-1792.

22. Patra, A.K. (2013) The effect of dietary fats on methane emissions, and its other effects on digestibility, rumen fermentation and lactation performance in cattle: A meta-analysis. Livest. Sci., 155: 244-254.

23. Gómez-Cortés, P., Frutos, P., Mantecón, A.R., Juárez, M., de la Fuente, M.A. and Hervás, G. (2008) Milk production, conjugated linoleic acid content, and in vitro ruminal fermentation in response to high levels of soybean oil in dairy ewe diet. J. Dairy Sci., 91: 1560-1569.

24. El-Sherbiny M., Cieslak, A., Pers-Kamczyc, E., Szczechowiak, J., Kowalczyk, D. and Szumacher-Strabel, M. (2016) Short communication: A nanoemulsified form of oil blends positively affects the fatty acid proportion in ruminal batch cultures. J. Dairy Sci., 99: 399-407.

25. Harfoot, C.G. and Hazelwood, G.P. (1997) Lipid metabolism in the rumen. In: Hobson, P.N., editor. The Rumen Microbial Ecosystem. Elsevier, New York, NY. p382-426.

26. Szczechowiaka, J., Szumacher-Strabel, M., El-Sherbiny, M., Pers-Kamczy, E., Pawlak, P. and Cieslak, A. (2016) Rumen fermentation, methane concentration and fatty acid proportion in the rumen and milk of dairy cows fed condensed tannin and/or fish-soybean oils blend. Anim. Feed Sci. Technol., 216: 93-107.

27. Boles, J.A., Kott, R.W., Hatfield, P.G., Bergman, J.W. and Flynn, C.R. (2005) Supplemental safflower oil affects the fatty acid profile, including conjugated linoleic acid, of lambs. J. Anim. Sci., 83: 2175-2181.

28. Noci, F., French, P., Monahan, F.J. and Moloney, A.P. (2007) The fatty acid composition of muscle fat and subcutaneous adipose tissue of grazing heifers supplemented with plant oil-enriched concentrates. J. Anim. Sci., 85: 1062-1073.

29. Roy, A., Mandal, G.P. and Patra, A.K. (2013) Evaluating the performance, carcass traits and conjugated linoleic acid content in muscle and adipose tissues of Black Bengal goats fed soybean oil and sunflower oil. Anim. Feed Sci. Technol., 185: 43-52.

30. Li, X.Z., Yen, C.G., Lee, H.G., Choi, C.W. and Song, M.K. (2012) Influence of dietary plant oils on mammary lipogenic 
enzymes and the conjugated linoleic acid content of plasma and milk fat of lactating goats. Anim. Feed Sci. Technol., 174: 26-35.

31. Lunsin, R., Wanapat, M., Yuangklang, C. and Rowlinson, P. (2012) Effect of rice bran oil supplementation on rumen fermentation, milk yield and milk composition in lactating dairy cows. Livest. Sci., 145: 167-173.

32. Dai, X.J., Wang, C. and Zhu, Q. (2011) Milk performance of dairy cows supplemented with rapeseed oil, peanut oil and sunflower seed oil. Czech. J. Anim. Sci., 56: 181-191.

$* * * * * * * *$ 